\title{
Stroke Rehabilitation
}

\author{
Chong Tae Kim \\ Division of Pediatric Rehabilitation Medicine, The Children's Hospital of Philadelphia, \\ Department of Physical Medicine E Rehabilitation, \\ The University of Pennsylvania, \\ USA
}

\section{Introduction}

Stroke is defined a sudden neurological impairment resulting from interruption of the blood supply and brain tissue damage. The most common symptom of a stroke is sudden weakness and/or numbness of the face, arms or legs, most often on one side of the body. Other symptoms include: confusion, difficulty speaking or understanding speech; difficulty seeing with one or both eyes; difficulty walking, dizziness, loss of balance or coordination; severe headache with no known causes; fainting or unconsciousness. Generally stroke means compromise of arterial blood supply (arterial stroke). Venous stroke is very rare in adult but not uncommon in children.

Strokes can be classified as either hemorrhagic or non-hemorrhagic (infarction). This classification helps to decide early therapeutic intervention. Hemorrhagic stroke is not indicated for t-PA (tissue plasminogen activator) protocol. Hemorrhagic stroke is most commonly related with hypertension or aneurysm in adults and with congenital vascular abnormality in children. Non-hemorrhagic stroke is more common than hemorrhagic stroke $(8: 2)$ in the United States and European countries ${ }^{1,2}$, however a more recent study shows 6:4 ratio ${ }^{3}$. This ratio varies in different races and cultures $^{4}$.

The diagnostic procedures of stroke are identical in both adult and children. A meticulous history and neurological examination are the mainstays of diagnosis. Head CT (computerized tomography) is useful to differentiate hemorrhagic and non-hemorrhagic stroke in very acute phase. A brain MRI (magnetic resonance image) is requested if head CT is not diagnostic. Intracranial as well as extracranial vessels can be evaluated by a MRA (magnetic resonance arteriography). MRV (magnetic resonance venography) is indicated for venous stroke diagnosis.

In very acute phase of stroke (within 3 hours), a thrombolytic agent (t-PA) is recommended as a standard treatment for non-hemorrhagic strokes in adult. It decreases mortality and improves functional outcome, in spite of hemorrhagic complications 5 .

\section{Right versus left hemisphere stroke}

Right hemisphere function is to control not only the movement of the left side of the body, but also analyze spatial orientation (distance, depth, position, size, and stereotaxis) and 
perceptual abilities. Stroke patients with right hemisphere lesion often demonstrate lack of safety awareness and impulsive behaviors. With these complex impairments, they have difficulties in re-learning ADL (activities of daily living). For example, they are unable to read or copy letters, forget to clean their left side body, or ignore to wear assistive devices for activity. Even though they can maintain speech-language function better than patients with left hemisphere stroke patients, they may make errors in grammar.

Major functions of the left hemisphere are to control the movements of the right side of the body and to maintain speech-language function. Patients with left hemispheric strokes sustain right hemiplegia and aphasia. They behave cautiously and need more time to complete the same task compared with right hemispheric stroke patients. Different types of aphasia can occur depending on the specific site of the lesion in the left hemisphere.

It is controversial whether rehabilitation outcomes differ depending on which hemisphere the lesion is occurs ${ }^{6-8}$. Possible reasons for the controversy are different outcome scales, measurement domain, presence of hemi-neglect, and evaluation timing. For example, if the outcome compared is vocational rehabilitation, patients with right hemisphere lesion show better outcome9. The higher percentage of patients returning to work with a right hemispheric lesion largely can be explained by preserved speech-language function. However patients with right hemispheric lesions more frequently develop social defects than those with left hemispheric lesions ${ }^{10}$. In contrast, if regaining arm function is measured as a rehabilitation outcome, poorer outcome is reported in right hemispheric lesions ${ }^{11}$.

Hemi-neglect develops more commonly in stroke patients who have right hemispheric lesion compared to the left. There is a wide range of incidence reported, because of different evaluation tools and evaluation timing12,13. Among patients with right hemispheric lesions, patients with hemi-neglect are more disabled and stay longer at rehabilitation facilities than those without hemi-neglect ${ }^{14}$. Again, one possible reason of controversy in outcomes of patients with stroke between right and left hemispheric lesions is that patients with a concurrent right hemispheric lesion with hemi-neglect has more disability than would be with a right hemispheric lesion alone ${ }^{15}$. Future studies excluding hemi-neglect patients may help clarify the difference in disability between right and left hemiplegia patients ${ }^{16}$.

\section{Hemorrhagic versus non-hemorrhagic stroke}

Stroke prognosis between hemorrhagic and non-hemorrhagic stroke, is another area of controversy ${ }^{17-19}$. It is largely attributed to the timing of outcome measurement and scopes of outcome. Not only matched comparison studies ${ }^{20,21}$, but also large population retrospective ones22-24 consistently showed better and faster functional recovery in hemorrhagic versus non-hemorrhagic stroke at short term outcomes. For long-term outcomes (one year poststroke), one study reported that there was no difference between hemorrhagic and nonhemorrhagic stroke22, but another study observed better outcome in non-hemorrhagic stroke $^{23}$. For further study, it is to be considered that $20-40 \%$ of initial ischemic infarction may develop hemorrhagic transformation within one week after initial stroke onset. Hemorrhagic transformation may blur the distinction between hemorrhagic and nonhemorrhagic strokes and therefore, the classification based on initial imaging studies can be a source of significant bias. 
In summary, hemorrhagic stroke has higher mortality rate than non-hemorrhagic in acute phase and often requires emergent surgical intervention for survival. However, hemorrhagic stroke survivors without significant surgical complications make better functional improvement in early phase of rehabilitation than those with non-hemorrhagic stroke.

\section{Impairments and disabilities sequelae to stroke}

Severity and types of impairments resulted from a stroke depend on stroke site and lesion size. Most common impairments are 1) motor dysfunction (paralysis of extremity, face, and oropharyngeal muscles), 2) sensory dysfunction (decreased sensation, perception disorder, abnormal sensation), 3) sphincter dysfunction (bowel and bladder incontinence), 4) cognitive dysfunction (anomia, aphasia, dementia), 5) emotional disturbance (depression, apathy).

1. Paralysis of one side of body (hemiplegia): It develops in very early phase of stroke. If stroke lesion is in the right hemisphere, paralysis develops in the left face and the extremity. But stroke lesion located in the right brainstem, develops paralysis in the right face and left extremity. Most patients with stroke complain of flaccid extremity as an initial symptom. The flaccid extremity usually evolves to spastic extremity as part of its natural course. Details of motor function recovery will be described in the follow section (Motor function recovery).

One side of bulbar muscle paralysis results in oropharyngeal dysfunction (dysphagia). Stroke patient with dysphagia needs non-oral feeding until safe swallowing recovered. Depending on the severity of dysphagia, stroke patient needs nasogastric or gastrostomy/jejunostomy tube feeding. VFSS (videofluorographic swallowing study), also called videofluorographic modified barium swallowing study, is a standard diagnostic test to evaluate swallowing function. Penetration is defined when a bolus moves aberrantly down to the vestibule above the true vocal fold. This may trigger a coughing or a choking reflex after swallowing the bolus. Aspiration occurs when a bolus passes farther down through the true vocal folds and enter into the trachea and lungs. Most of patients with dysphagia return to a regular diet in early post-stroke phase 25,26 . Compared to other lesions, dysphagia develops more common and less favorable outcome in brainstem stroke, however $88 \%$ returned to regular oral intake 4 months after stroke ${ }^{27}$. Tracheostomy increases the risk of aspiration because of the limitation of laryngeal elevation during swallowing. Selection of adequate texture of meals and meticulous monitoring of swallowing are critical to prevent aspiration.

2. Sensory impairment: stroke patients have sensory impairment of peripheral and/or central sensation. Peripheral sensory impairments include hypesthesia/paresthesia, loss of proprioception and position, or loss of pain/temperature. Agraphesthesia and astreognosis is seen in central sensory impairment. Those impairments cause stroke patients to needs more assistance for learning motor and cognitive skills. Reception is the processing of registration of sensations or stimuli which are collected through sensory organs (nose, eye, ear, skin, tongue, joint, or internal organs). Received sensations or stimuli are conveyed to the corresponding primary sensory cortexes. For example, visual sensation reaches occipital cortex via optic pathways. Perception is the next process to interpret the received sensations or stimuli. Perception is higher cortical function than reception and many parts of brain are involved. Details of perception disorder will be discussed in the following perception disorder. 
3. Sphincter dysfunction: Double incontinence (both urinary and fecal incontinence) is more common than isolated urinary or fecal incontinence in stroke patients ${ }^{28}$. Even though this impairment resolved during early post-stroke period, persistent urinary incontinence was reported $10-20 \%$ at the time of discharge from rehabilitation ${ }^{28,} 29$. The most common type of bladder dysfunction is uninhibited type. It is usually resolved with timed voiding training. Sometimes anti-cholinergic agents (oxybutynin, tolterodine) are indicated to relax bladder. Most of sphincter dysfunction is restored as other functional recovery occurs. Nocturnal incontinence may persist in chronic phase. Unawareness of bladder is a strong negative prognostic factor for urinary incontinence, in addition to cognitive impairment and lower limb dysfunction. It may be a lifelong disability in those with significantly cognitive impaired.

4. Cognitive dysfunction is the most powerful negative factor for outcome. This is most commonly and severely impaired in patients with left hemisphere lesion with aphasia. It is also very closely negatively correlated with returning to work. $38 \%$ of stroke patients were found to have cognitive impairment assessed by Mini-Mental State Examination at 3 month post-stroke and more common in elderly ( $>75$ years), low socioeconomic status, and left hemisphere lesion ${ }^{30}$. It has strong correlations with longterm outcome. $30-50 \%$ of stroke survivors were categorized in lower levels on most measures of neuropsychological testing and information processing is the most common and the worst deficit 31 . Cognitive impairment and dementia after a stroke can be reduced by adequate treatment of hypertension and acetylcholinesterase inhibitors (donepezil, galantamine, rivastigmine), prescribed to alzheimer's disease, and may be beneficial for cognitive rehabilitation ${ }^{32}$, 33. A randomized placebo-controlled double blind study reports that greater improvement of language function in verbal fluency and repetition was found in patients receiving levedopa than placebo ${ }^{34}$. One open label case study shows rapid improvement in cognitive as well as physical function in three chronic stroke patients with perispinal etanercept $\mathrm{t}^{35}$.

5. Emotional disturbance: Right hemispheric stroke patients sustain behavioral changes, which in turn caused family conflicts with this altered behaviors ${ }^{36}$. A 5 year longitudinal study shows about 30\% of stroke survivors sustained depression and $48 \%$ were not depressed at any time of evaluation ${ }^{31,37}$. Also depression was not static, but resolved and newly developed at any time in the 5 year follow-up 37 . High risk factors of depression include stroke severity, unemployment, and cognitive impairment. A patient with depression prior to stroke has 9 times higher risk of post-stroke depression ${ }^{38}$. The frequency of post-stroke apathy is reported $20-25 \%$ and commonly conjunct with cognitive impairment and depression ${ }^{39}$. Dopaminergics or neurostimulants (methylphenidate, dexamphetamine) is reportedly beneficial to apathy ${ }^{40-43}$.

Post-stroke depression is a strong negative factor for functional recovery, however there is no standard pharmacological treatment. A double-blind controlled study with fluoxetine and nefiracetam did not support therapeutic effectiveness for either agent 44 , 45 , however, a matched comparison study with milnacipran revealed effectiveness ${ }^{46}$. The controversy is in part ascribed to uncovered pharmacodynamics of anti-depressant in stroke. Systemic review of pharmacological management of post-stroke depression concludes there is insufficient evidence to support anti-depressant administration for prevention or to improve recovery, but the medications may improve mood in poststroke depression ${ }^{47}$. 


\section{Perception disorder}

Perception is the conscious mental process through the senses of existence and external sensory stimulus. Visual perception disorders are manifested as agnosia, alexia, apraxia, hemi-neglect, spatial disorientation. Hemispatial neglect is synonymous with hemiagnosia, hemi-neglect, unilateral neglect, unilateral inattention. Homonymous hemianopsia differs from visual hemi-neglect. While the former is resulted from the lesion of the visual track and the patient with this impairment uses compensate strategy (for example, head turning), the latter is spatial inattention to one side of body resulted from parietal cortex and one with this impairment does not compensate. Perception disorders impede not only functional recovery, but safety awareness. For example, perceptual disorder of position leads the patient stands with asymmetric weight bearing and affects gross motor function recovery. Patients with right hemisphere stroke predominantly sustain spatial perception disorders. Perceptual training with mirror therapy, prism adaption, eye patch, reportedly improves functional outcomes after stroke, but one large review article showed insufficient supportive data of perceptual intervention (visual field deficits, neglect/inattention, and apraxia were excluded in this study) 48,49 .

Apraxia is the inability to carry out familiar, purposeful tasks without sensory or motor impairment, especially difficult is proper use of an object. Patients with speech apraxia demonstrate incomplete speech with repetition, omission, or distorted words. They are doing well with short simple conversations (How are you? Are you OK?...), but the impairment is exaggerated with long complex sentences. Patients with ideational apraxia have difficulties in coordination of sequential performance. For example, he/she knows how to hold a letter, to put it into an envelope, and to attach a stamp. But when he/she is requested to do these three steps sequentially, he/she cannot do this in the proper order. Clinically, it is manifested as difficulties in eating, dressing, and bathing. A patient with ideomotor apraxia is unable to respond properly to a request or command. He/she knows the name of an object, but not able to use properly. For example, when he/she is asked to brush hair with a comb, the patient demonstrates improper usage of the comb. Constructional apraxia is the inability to copy, draw, or construct simple figures. The patient with this impairment draws a face unproportionally. Dressing apraxia, difficulty in wearing cloths, is a misnomer (not true apraxia). This is resulted from the impairment of spatial perception, which makes it difficult to recognize and match the parts of the body and the cloth correctly.

Pain perception disorder: Central post-stroke pain syndrome (CPSP) is one of devastating complications and formerly called thalamic pain syndrome. It is understood that damaged spinothalamic track may play a key role in pathogenesis, but not always. It may develop independently or jointly with complex regional pain syndrome (CRPS). Clinical findings are very similar to CRPS, however, CPSP is confined to hemiplegic face or limbs only. Both the presence of sensory disturbances and neurpathic pain differentiates CPSP from CRPS. It usually develops 1-3 months after stroke onset, but sometimes develops in a chronic phase. Plain radiographic study is recommended to rule out musculoskeletal lesion of the shoulder or hand. In order to rule out deep vein thrombosis, Doppler ultrasound study is useful. Triple phase bone scan is to be considered if CRPS suspected. Therapeutic options are similar to CRPS. Magnetic motor cortex stimulation 50 , vestibular stimulation ${ }^{51,52}$, or deep vein stimulations ${ }^{53}$ are being tried in some cases. 


\section{Motor function recovery}

Hemiplegia is the most paramount clinical feature, which is described as sided weakness of extremity, facial droop, and slurred speech. Motor function recovery follows stereotypic patterns. It initially develops flaccid hemiplegia during the acute phase. Depending on individual cases, however, flaccid hemiplegia evolves into spastic hemiplegia. It continues to evolve into spastic synergy. Typically, flexion synergy develops in hemiplegic upper extremity and extension synergy in the lower extremity. As the synergy fades, individual movement of joints emerges. The longer the length of time in flaccid hemiplegia, the poorer the prognosis of motor recovery. Motor recovery may stagnate at any phase and may skip phases. Another pattern is that proximal segment of extremity function recovers earlier than distal one. Many patients with stroke sustain typical stereotyped poor dexterity and hemiplegic gait because of residual distal extremity dysfunction. In order to facilitate motor recovery, comprehensive rehabilitation modalities, such as anti-spastic medications, orthotics, and therapeutic exercise are cooperated. Significant motor recovery usually occurs in the first three months after stroke. Further recovery may continue in the next three months but less extensive.

Brunnstrom stage describes the evolution of hemiplegia ${ }^{54}$. Flaccid paralyzed extremity is seen at stage 1; Mild spasticity is appreciated in the flaccid paralyzed extremity at stage 2; The spasticity increases and some self-activated synergic movement of the paralyzed extremity begins at stage 3; Dominant stereotyped self-activated synergic movement of the paralyzed extremity is more prominent at stage 4 ; decreasing synergic movement pattern with emerging individual movement of the paralyzed extremity is the hall mark of the stage 5; normal movement pattern is seen at stage 6 . Not all paralyzed extremity evolves from stage 1 to 6 . Depending on stroke severity and recovery potential, the stages may progress quickly or may be skipped. Generally speaking, hemiplegia with short or absent stage 1 has better recovery; the longer the stage 1 , the worse prognosis; the lower stage, the poorer outcome, 11, 55-58.

In addition to Brunnstrom stage, motor function recovery tends to begin in the proximal segment and then to progress to the distal segments of the extremity. This tendency is common in both upper and lower extremity. Most of stroke patients are able to move their proximal segments of arms and legs at the time of discharge from inpatient rehabilitation. However, many stroke patients sustain significant paralysis of the distal segments of arm and leg. Because of this residual impairment, most stroke survivors have difficulties to be independent with ADLs and ambulation. Another common finding is that motor recovery of the lower extremity is better than that of the upper extremity. Why is motor recovery of the proximal segments and the lower extremity better than that of the distal segments and the lower extremity? It can be partially explained by topographic distribution in the brain (the cortex corresponding to hand is much larger than one to foot in the brain) and higher developmental hierarchy (hand function develops later than foot function). Compared to the proximal segments or foot function, more neurons and synapses are to be involved to maintain functions of the distal segments or hand.

\section{Rehabilitation}

The priorities at the acute care unit are both diagnostic as well as therapeutic interventions. Depending on medical conditions (hemorrhagic or non-hemorrhagic lesion, size and site of 
stroke, underlying health status,...), treatment options are determined. It is suggested that early rehabilitation intervention is necessary, even if diagnostic or therapeutic plan are not completed. At this phase, rehabilitation starts with less intensive approach. Passive range of motion, position changes, stimulation control, safe feeding, and joint contracture prevention are important to prevent impending complications.

Functional improvement is not always parallel with neurological recovery in patients with stroke. Analysis of the Uniform Data System for Medical Rehabilitation (UDSMR) for stroke patients in US from 2000 to 2007 shows decreased a mean length of rehabilitation unit stay from 19.6 days to 16.5 days, decrease a mean FIM (functional independence measurement) at rehabilitation unit from 62.5 to 55.1 (means more functionally dependent patients were admitted to rehabilitation unit), decrease a mean FIM at discharge from rehabilitation unit from 86.4 to 79.8 (means less functionally independent patients were discharged from rehabilitation unit), but the FIM change during rehabilitation stay remained relatively stable $^{59}$. These results reflect that patients with stroke in US admit and discharge earlier than before. Patients with stroke may benefit from early discharge, but by the other hand, early discharge from rehabilitation unit increased the mortality ${ }^{60}$.

From an ADL (activities of daily living) standpoint, stair walking (downward more difficult than upward) is the hardest to be improved, and then tub/shower transfer, ambulation, and lower body dressing follow. In contrast, eating is the easiest to be improved, and then grooming, and sphincter control follow.

Poor sitting balance, poor trunk control, urinary incontinence, severity of disability, and old age (>74 years) are poor predictors for independent walking ${ }^{61}$. Standing balance ability is more important than lower extremity strength to achieve better ambulation ${ }^{62}$.

In cognitive rehabilitation, problem solving is the most severely impaired and the least potential for recovery after stroke. Learning and memory impairments are most common ${ }^{10}$. Comprehension and expression are less impaired and better improved than memory. Patients with right hemiplegia are more impaired and less likely to improve in cognitive functions than those with left hemiplegia.

Cognitive and speech-language impairment prevents patients with stroke from participation in social activities. Patients with higher cognitive level recover much better than ones with lower level. A study of return to work reports 1) no significant racial differences in left hemisphere infarction, but whites were more likely to return to work in right hemisphere infarction, 2) no significant difference of returning to work between whites and non-whites with left hemisphere infarction, 3) whites with right hemisphere infarction are most likely to return to work, while non-whites with right hemisphere infarction are least likely, 4) patients employed premorbidly at professional or managerial position, younger age group, less severe disability, white race, right hemisphere lesion were more likely to return to work following a cerebral infarction?.

\section{Traditional and new therapeutic approaches to stroke rehabilitation}

Traditional physical therapy and occupation therapy are still largely mainstays of the rehabilitation. Many therapeutic techniques to facilitate movement of paralyzed side, based on motor developmental hierarchy, repetition of motor pattern, and task-oriented training. 
Abnormal muscle tone leads to abnormal positioning and abnormal movement pattern, and vice versa. To break this vicious cycle, comprehensive rehabilitation should include muscle tone management, proper bracing and positioning, and stimulation control. Repetitive task training is a commonly used in current rehabilitation therapy, but a literature review reported it is not effective in upper extremity motor function ${ }^{63}$.

Constraint-induced movement therapy (CIMT or CIT) was introduced with a hypothesis of forceful usage of paralytic arm facilitate neuroplasticity of the brain, which in turn leads to recovery of the arm motor function ${ }^{64}$. There are many supportive reports to its effectiveness 65,66 , however, there is a lack of large randomized controlled study ${ }^{67}$. CIMT is indicated for subjects who have no significant spasticity and some strength of the paralyzed upper extremity. It is not effective in acute phase of stroke ${ }^{68}$.

Development in neruoscience and computer technology provides novel ideas to overcome the limitation of traditional rehabilitation for stroke. Originally, robotic treatment was introduced to alleviate the labor-intensive aspects of physical therapy by preinstalled programs to perform a goal-directed movement autonoumously or semi-autonomously ${ }^{69}$. It induces movement of paralyzed limbs by activation of the motor cortex of the side of the lesion and the movement of the limb also activates the motor cortex in a positive feedback. Most of devices are designed to lead task-oriented movement by intensive repetitive patterns. Functional brain MRI studies of robotic treatments, demonstrated an increased activation of the sensorimotor cortex during grasping tasks greater than non-practiced $\operatorname{tasks}^{70}$. However, the effectiveness of robotic treatment is still in question ${ }^{71-73}$. It is likely effective for shoulder and elbow function recovery, but may lack effectiveness of hand function improvement.

EEG/MEG-based motor imagery brain-computer interface utilizes neuronal activities of the motor cortex of lesion side while performing motor imagery ${ }^{74,75}$. Currently combined braincomputer interface with robotic feedback technique is being tried ${ }^{76}$.

Virtual reality training, although needs further study, appears to be effective in improvement of motor function 77,78 .

\section{Prognostic factors}

Generally, poor prognostic factors include prolonged flaccidity of paralyzed limb, right hemisphere lesion with hemi-neglect, cognitive impairment, old age (>74 years), anterior circulation, and large lesion size. Also spouse at home, hypothermia at acute phase, and absent co-morbidities are good predictors ${ }^{79}, 80$.

\section{Focus on pediatric stroke}

Pediatric stroke is classified into infant and childhood stroke. Infant (neonatal or perinatal) stroke is defined as occurring between 28 weeks gestation and 28 days of postnatal age. The incidence is estimated as one in every four thousand live birth per year in the United Sates ${ }^{81}$. Ischemic stroke is twice as common as hemorrhagic stroke. According to a retrospective review, the most common discharge diagnoses conjunction with neonatal stroke included infection, cardiac disorders, and blood disorders. Less than 5\% was associated with birth asphyxia $^{81}$. 
Childhood stroke is defined as occurring between 30 days of postnatal age and 18 years old. The incidence is reported 2-3/100,000 per year in US81, 2.7/100,000 in Canada (ischemic stroke only) ${ }^{82}$, and 13/100,000 in France ${ }^{83}$. Its mortality rate is reported $7-28 \%$ and higher in males than females and in blacks than white, respectively. Stroke is less common in children than in adults, but is one of the top ten causes of death in children in the US. It results in one of the leading causes of disability in young generations. The pathophysiology of childhood stroke is same as adults, but underlying premorbidities or etiologies are different. Most of adult stroke patients have pre-existing medical conditions, such as hypertension, diabetes mellitus, hyperlipidemia, arteriosclerosis, heart disease, or obesity, but in contrast one third of child stroke patients do not have any evident pre-existing medical conditions. In childhood stroke, congenital heart disease is the most common known etiology (about 30\%), and sickle cell disease is the leading cause of stroke in African American ethnic group. Arteriovenous malformation is the leading cause of hemorrhagic stroke in childhood. Various coagulation disorders-factor V Leiden and prothrombin mutation, protein $\mathrm{C}$ and $\mathrm{S}$ deficiency, anti-phospholipid antibody, and inherited coagulation abnormalities and arterial vasculitis are related to pediatric strokes. Venous stroke is not uncommon in children. Venous:arterial stroke ratio is 1:4-6 in non-hemorrhagic stroke ${ }^{84}$. Venous stroke develops, when cerebral venous drainage to the internal jugular veins is significantly obstructed by thrombosis in the cerebral venous sinus (sinus venous thrombosis). The obstructed venous drainage consequently impedes arterial supply to the brain. Progressive insufficient arterial supply to the brain eventually leads to ischemia. Because of this slow process, compared with arterial stroke, clinical symptoms and signs progress slowly in venous stroke. High risks of sinus venous thrombosis are head and neck infection (meningitis, mastoiditis), dehydration, coagulation disorder, and perinatal complications. The outcome of a venous stroke is excellent.

The ratio of hemorrhagic to nonhemorrhagic stroke in childhood stroke is about 5:3 in the US 85 . It is understood that the incidence of homorrhagic stroke is higher than adult, but it is similar to a recent stroke registry data $^{3}$. Diagnostic interventions of pediatric stroke are similar to those of adult stroke. In addition, hematologic and metabolic work up for coagulopathy is important. It is not easy to recognize neonatal stroke because of limited clinical presentations. It is partially plausible to explain that patients with hemiplegic cerebral palsy might have unrecognized neonatal stroke. It is supported by the fact that patients with hemiplegic cerebral palsy showed elevated antiphospholipid and/or factor $\mathrm{V}$ Leiden mutation than normal control ${ }^{86-87}$. Patients with sickle cell disease has 200-400 times high risk and $50 \%$ of recurrence risk by three years.

In order to prevent stroke recurrence, aspirin is recommended for high risk of stroke patients in both adult and children. Apirin used for stroke prophylaxis does not complicate Reye's syndrome in children. Regular brain MRA is suggested to patient with hemorrhagic stroke secondary to aneurysm.

Since human cerebral hemispheres are already specialized at an early stage of development, pediatric stroke patients also demonstrate adult pattern of side specificity for brain lesions ${ }^{88-89}$. Therefore clinical features are side specific and similar to adult stroke.

Outcomes vary among studies because of differences in population characteristics, stroke type, duration of follow-up, and outcomes measurement tools. Long-term outcome study 
showed complete recovery rate without residual impairment in 14\% of patients with nonhemorrhagic stroke $\mathrm{e}^{90}$ and $25 \%$ in hemorrhagic stroke ${ }^{91}$, respectively. In adult strokes, hemorrhagic stroke has higher mortality (23\%) than non-hemorrhagic stroke ${ }^{91}$.

In the long-term, cognitive impairment is significant in childhood stroke, and IQ (Intellectual Quotation) ranges widely and is lower than average ${ }^{90,92,93}$. As imagined, VIQ (Verbal IQ) is higher than PIQ (Performance IQ) in children with right hemisphere lesion, and PIQ is higher than VIQ in left hemisphere lesion ${ }^{90,}{ }^{93}$. In spite of cognitive impairment, most of children return to mainstream school with/without support57, 90. Regardless of residual impairments and disabilities, they feel healthy and happy as normal children would ${ }^{94}$.

General survival rate of pediatric stroke is better than adults ${ }^{95,96.5}$ year survival rate is $85 \%$, and residual neurological deficits of $75 \%$ (hemiparesis, epilepsy, learning disabilities, visual field deficits, mental retardation) ${ }^{97}$. Idiopathic stroke have better prognosis than stroke associated with cardiac disease ${ }^{98}$. It is controversial but generally age is also an important prognostic factor ${ }^{98}$. The functional outcome of childhood stroke is more favorable than that of adult one. However, it is reported that infant stroke has poorer outcome than childhood stroke.

Poor outcome predictors are multiple cortical dysfunction, initial symptoms with altered level of consciousness with/without seizure, middle cerebral artery lesion, infant age onset, persistence of hemiparesis 1 month after stroke, and bilateral hemisphere lesions 57,90, 93,99, 100 .

School re-entry is the final rehabilitation goal for children with stroke. A neuropsychological test including IQ indicates the details of the cognitive impairments. Based on the test results, school re-entry might be planned. Depending on medical conditions and the test results, home bound education, part time student, full time student, or classroom modification might be advised.

\section{References}

[1] Feign VL, Lawes CM, Bennett DA, Anderson CS. Stroke epidemiology: a review of population-based studies of incidence, prevalence, and case-fatality in the late $20^{\text {th }}$ century. Lancet Neurol 2:43-53, 2003.

[2] Lauretani F, Saccavini M, Zaccaria B, Agosti M, Zampolini M, Franceschini M. Rehabilitation in patients affected by different types of stroke: A one-year followup study. Eur J Phys Rehabil Med 46(4):511-516, 2010.

[3] Shiber JR, Fontane E, Adewale A. Stroke registry: hemorrhaic vs ischemic strokes. Am J Emerg Med 28(3): 331-333, 2010.

[4] Wei JW, HeeleyEL, Wang J-G, Huang Y, Wong LKS, Li Z, Heritier S, Arima H, Anderson CS. Comparison of recovery patterns and prognostic indicators for ischemic and hemorrhagic stroke in China: the ChinaQUEST (Quality evaluation of stroke care and treatment) registry study. Stroke 41:1877-1883, 2010.

[5] Wardlaw JM, Murray V, Berge E, Del Zoppo GJ. Thrombolysis for acute ischemic stroke. Cochrane Database of Systematic Reviews (4):CD000213, 2009.

[6] Coughlan AK, Humprey M. Presenile stroke: long term outcome for patients and their families. Rheumatol Rehabil 21:115-120, 1982. 
[7] Goto A, Okuda S, Ito S, Matsuoka Y, Ito E, Takahashi A, Sobue G. Locomotion outcome in hemiplegic patients with middle cerebral artery infarction: the difference between right- and left-sided lesions. J Stroke Cerebrovasc Dis 18(1):60-67, 2009.

[8] Fink JN, Frampton CM, Lyden P, Lees KR, Virtual International Stroke Trials Archives Investigators. Dose hemispheric lateralization influence functional and cardiovascular outcomes after stroke?: an analysis of placebo-treated patients from prospective acute stroke trials. Stroke 39(2):3335-3340, 2008.

[9] Howard G, Till JS, Toole JF, Matthews C, Truscott BL. Factors influencing return to work following cerebral infarction. JAMA 253(2):226-232, 1985.

[10] Mosch SC, Max JE, Tranel D. A matched lesion analysis of childhood versus adult-onset brain injury due to unilateral stroke. Cog Behav Neurol 18(1):5-17, 2005.

[11] Kwakkel G, Kollen BJ, van der Grond J, Prevo AJH. Probability of regaining dexterity in the flaccid upper extremity: impact of severity of paresis and time since onset in acute stroke. Stroke 34:2181-2186, 2003.

[12] Stone SP, Patel P, Greenwood RJ, Halligan PW. Measuring visual neglect in acute stroke and predicting its recovery: the visual neglect recovery index. J Neurol Neurosurg Psychiatry 55:431-436, 1992.

[13] Bowen A, McKenna K, Tallis R. Reasons for variability in the reported rate of occurrence of unilateral spatial neglect after stroke. Stroke 30:1196-1202, 1999.

[14] Katz N, Hartman-Maeir A, ring H, Soroker N. Functional disability and rehabilitation outcome in right hemisphere damage patients with and without unilateral spatial neglect. Arch Phys Med Rehabil 80:379-384, 1999.

[15] Buxbaum LJ, Ferraro MK, Veramonti T, Farne A, Whyte J, Ladavas E, Frassinetti F. Coslett HB. Hemispatial neglect: subtypes, neuroanatomy, and disability. Neurol 62:749-756, 2004.

[16] Jehkonen M, Ahonen J-P, Dastidar P, Koivisto A-M, Laippala P, Vilkki J, Molnar G, Predictors of discharge to home during the first year after right hemisphere stroke. Acta Neurol Scand 104:136-141, 2001.

[17] Jorgensen HS, Nakayama H, Raaschou HO, Olsen TS. Intracerebral hemorrhage versus infarction: stroke severity, risk factors, and prognosis. Ann Neurol 38(1):45-50, 1995.

[18] Leung AW, Cheng SK, Mak AK, Leung KK, Li LS, Lee TM. Functional gain in hemorrhagic stroke patients is predicted by functional level and cognitive abilities measured at hospital admission. Neurorehabil 27(4):351-358, 2010.

[19] Katrak PH, Black D, Peeva V. Do stroke patients with intracerebral hemorrhage have a better functional outcome than patients with cerebral infarction? PM\&R 1:427-433, 2009.

[20] Paolucci S, Antonucci G, Grasso MG, Bragoni M, Coiro P. Functional outcome of ischemic and hemorrhagic stroke patients after inpatient rehabilitation: A matched comparison. Stroke 34:2861-2865, 2003.

[21] Chae J, Zorowitz RD, Johnston MV. Functional outcome of hemorrhagic and nonhemorrhagic stroke patients after in-patient rehabilitation. Am J Phys Med Rehabil 75:177-182, 1996.

[22] Franke CL, van Swieten JC, Algra A, van Gijin J. Prognostic factors in patients with intracerebral hematoma. J Neurol Neurosurg Psychiatry 55:653-657, 1992. 
[23] Wei JW, Heeley EL, Wang JG, Huang Y, Wong LKS, Li Z, Heritier S, Arima H, Anderson CS. Comparison of recovery patterns and prognostic indicators for ischemic and hemorrhagic stroke in China: the ChinaQUEST(Quality evaluation of stroke care and treatment) registry study. Stroke 41:1877-1883, 2010.

[24] Toschke AM, Tilling K, Cox AM, Rudd AG. Heuschmann PU. Wolfe CD. Patientspecific recovery patterns over time measured by dependence in activities of daily living after stroke and post-stroke care: the South London Stroke Register (SLSR). Eur J Neurol 17:219-225, 2010.

[25] Daniel SK, Ballo LA, Mahoney M-C, Foundas AL. Clinical predictors of dysphagia and aspiration risk: outcome measures in acute stroke patients. Arch Phys Med Rehabil 81:1030-1033, 2000.

[26] Smithard DG, O'Neill PA, England RE, Park CL, Wyatt R, Martin DF, Morris J. The natural history of dysphagia following a stroke. Dysphagia 12(4):188-193, 1997.

[27] Meng N-H, Wang T-G, Lien I-N. Dysphagia in patients with brainstem stroke: incidence and outcome. Am J Phys Med Rehabil 79(2):170-175, 2000.

[28] Kovindha A, Wattanapan P, Dejpratham P, Permsirivanich W, Kuptniratsiku V. Prevalence of incontinence in patients after stroke during rehabilitation: a multicenter study. J Rehabil Med 41(6):489-491, 2009.

[29] Wilson D, Lowe E, Hoffman A, Rudd A, Wagg A. Urinary incontinence in stroke: results from the UK National Sentinel Audits of Stroke 1998-2004. Age \& Ageing 37(5):542-546, 2008.

[30] Patel MD, Coshall C, Rudd AG, Wolfe CD. Cognition impairment after stroke: clinical determinants and its association with long-term stroke outcomes. J Am Geriatr Soc 50:700-709, 2002.

[31] Barker-Collo S, Feigin VL, Parag V, Lawes CM, Senior H. Neurol Auckland Stroke Outcome Study. Part2: cognition, and functional outcomes 5 years poststroke. Neurol 75(18):1608-1616, 2010

[32] Rojas-Fernandez CH, Moorhouse P. Current concepts in vascular cognitive impairment and pharmacotherapeutic implications. Ann Pharmocotherapy 43(7):1310-1323, 2009.

[33] Narasimhalu K, Effendy S, Sim CH, Lee JM, Chen I, Hia SB, Xue HL, Corrales MP, Chang HM, Wong MC, Chen CP, Tan EK. A randomized controlled trial of rivastigmine in patients with cognitive impairment no dementia because of cerebrovascular disease. Acta Neurol Scand 121(4):217- 224, 2010.

[34] Seniow J, Litwin M, Litwin T, Lesniak M, Czlonkowska A. New approach to the rehabilitation of post-stroke focal cognitive syndrome: effect of levedopa combined with speech and language therapy on functional recovery from aphasia. J Neurol Sci 283(1-2):214-218, 2009.

[35] Tobinick E. Rapid improvement of chronic stroke deficits after perispinal etanercept: three consecutive cases. CNS Drugs 25(2):145-155, 2011.

[36] Morris J. Effects of right hemisphere strokes on personality functioning. Topics Stroke Rehabil 16(6):425-430, 2009.

[37] Ayerbe L, Ayis S, Rudd AG, Heuschmann PU, Wolfe CD. Natural history, predictors, and association of depression 5 years after stroke: the South London Stroke Register. Stroke 42(7): 1907-1911, 2010. 
[38] Ried LD, Jia H, Cameron R, Feng H, Wang X, Tueth M. Does prestroke depression impact poststroke depression and treatment? Am J Geriatr Psychiatry 18(7):624-633, 2010.

[39] Jorge RE, Starkstein SE. Robinson RG. Apathy following stoke. Canad J Psychiatry 55(6):350-354, 2010

[40] van Reekum R, Stuss DT, Ostrander L. Apathy:why care? J Neuropsychiatry Clin Neurosci 17:7-19, 2005.

[41] Long D, Young J, Dexamphetamine treatment in stroke. Q J Med 96:673-685, 2003

[42] Padala PR, Burke WJ, Bhatia SC, Petty F. Treatment of apathy with methylphenidate. J Neuropsychiatry Clin Neurosci 19:81-83, 2007.

[43] Spiegel DR, Kim J, Greene K, Conner C, Zamfir D. Apathy due to cerebrovascular accidents successfully treated with methylphenidate: a case series. J neuropsychiatry Clin Neurosci 21(2):216-219, 2009.

[44] Choi-Kwon S, Han SW, Kwon SU, Kang DW, Choi JM, Kim JS. Fluoxetine treatment in poststroke depression, emotional incontinence, and anger proneness: a double-bind , placebo-controlled study. Stroke 37(1):156-161, 2006.

[45] Robinson RG, Jorge RE, Clarence-Smith K. J Neuropsychiatry Clin Neurosci 20(2):178$84,2008$.

[46] Yamakawa Y, Satoh S, Sawa S, Ohta H, Asada T. Efficacy of milnacipran on poststroke depression on inpatient rehabilitation. J Psychiatry Clin Neurosci 59(6):705-710, 2005.

[47] Hackett ML, Anderson CS, House AO. Management of depression after stroke: a systematic review of pharmacological therapies. Stroke 36(5):1098-1103, 2005.

[48] Bowen A, Knapp P, Gillespie D, Nicholson DJ, Vail A. Non-pharmacological interventions for perceptual disorders following stroke and other adult-acquired, non-progressive brain injury. Cochrane Database of Systematic Reviews 4:CD007039, 2011.

[49] Jutai JW, Bhogal SK, Foley NC, Bayley M, Teasell RW, Speechley MR. Treatment of visual perceptual disorders post stroke. Topics Stroke Rehabil 10(2):77-106 , 2003.

[50] Tanei T, Kajita Y, Noda H, Takebayashi S, Nakatsubo D, Maesawa S, Wakabayashi T. Efficacy of motor cortex stimulation for intractable central neuropathic pain: comparison of stimulation parameters between post-stroke pain and other central pain. Neuro Medico-Chirug 51(1):8-14, 2011.

[51] McGeoch PD, Williams LE, Song T, Lee RR, Huang M, Ramachandran VS. Post-stroke tactile allodynia and its modulation by vestibular stimulation: a MEG case study. Acta Neurol Scand 119(6):404-409, 2009.

[52] McGeoch PD, Williams LE, Lee RR, Ramachandran VS. Behavioral evidence for vestibular stimulation as a treatment for central post-stroke pain. J Neurol Neurosurg Psychiatry 79(11):1298-1301, 2008.

[53] Pickering AE, Thornton SR, Love-Jones SJ, Steeds C, Patel NK. Analgesia in conjunction with normalization of thermal sensation following deep brain stimulation for central post-stroke pain. Pain 147(1-3):299-304, 2009.

[54] Twitchell TE. The restoration of motor function following hemiplegia in man. Brain 74:443-480, 1951. 
[55] Hashimoto K, Higuchi K, Nakayama Y, Abo M. Ability for basic movement as an early predictor of functioning related to activities of daily living in stroke patients. Neurorehabil Neural Repair 21(4):353-357, 2007.

[56] Yamanaka T, Ishii M, Suzuki H. Short leg brace and stroke rehabilitation. Top Stroke Rehabil 11(3):3-5, 2004.

[57] Kim CT, Han J, Kim H. Pediatric stroke recovery: a descriptive analysis. Arch Phys Med Rehabil 90(4):657-662, 2009.

[58] Wandel A, Jorgensen HS, Nakayama H, Raaschou HO, Olsen TS. Prediction of walking function in stroke patients with initial lower extremity paralysis: the Copenhagen Stroke Study. Arch Phys Med Rehabil 81:736-738, 2000.

[59] Granger CV, Markello SJ, Graham JE, Deutsch A, Ottenbacher KJ. The Uniform Data System for Medical Rehabilitation: report of patients with stroke discharged from comprehensive medical programs in 2000-2007. Am J Phys Med Rehabil 88:961-972, 2009.

[60] Ottenbacher KJ, Smith PM, Illig SB, et al. Trends in length of stay, living setting, functional outcome, and mortality following medical rehabilitation. JAMA 292:1687-1695, 2004.

[61] Duarte E, Marco E, Muniesa JM, Belmonte R, Aguilar JJ, Escalada F. Early detection of non-ambulatory survivors six months after stroke. Neurorehabil 26(4):317-323, 2010.

[62] Kollen B, van de Port I, Lindeman E, Twisk J, Kwakkel G. Predicting improvement in gait after stroke: a longitudinal prospective study. Stroke 36(12):2676-2680, 2005.

[63] Frech B, Thomas LH, Leathley MJ, Sutton CJ, McAdam J, Forster A. Langhorne P, Price CI, Walker A, Watkins CL. Repetitive task training for improving functional ability after stroke. Cochrane Database Syst Rev 17(4):CD006073, 2007.

[64] Taub E, Miller NE, Novack TA, Cook III EW, Fleming WC, Nepomuceno CS, Connell JS, Crago JE. Technique to improve chronic motor deficit after stroke. Arch Phys Med Rehabil 74:347-354, 1993.

[65] Wolf SL, Winstein CJ, Miller JP, Taub E, Uswate G, Morris D, Giuliani C, Light KE, Nicholas-Larsen D: EXCITE investigators. Effect of constraint-induced movement therapy on upper extremity function 3 to 9 months after stroke: the EXCITE randomized clinical trial. JAMA 296(17):2095-2104, 2006.

[66] Wolf SL, Thompson PA, Winstein CJ, Miller JP, Blanton SR, Nicholas-Larsen D, Morris D, Uswate G, Taub E, Light KE, Sawaki L. The EXCITE stroke trial: comparing early and delayed constraint-induced movement therapy. Stroke 41(10):2309-2315, 2010.

[67] Corbetta D, Sirtori V, Moja L, Gatti R. Constrained-induced movement therapy in storke patients: systematic review and meta-analysis. Europ J Physical Med \& Rehabil 46(4):537-544, 2010.

[68] Dromerick AW, Lang CE, Birkenmeier RL, Wagner JM, Miller JP, Videen TO, Powers WJ, Wolf SL, and Edwards DF. Very early constraint-induced movement during stroke rehabilitation (VECTORS): a single-center RCT. Neurol 73:195-201, 2009.

[69] Lum PS, Burgar CG, Shor PC, et al. Robot-assisted movement training compared with conventional therapy techniques for the rehabilitation of upper-limb motor function after stroke. Arch Phys Med Rehabil 83(7): 952-959, 2002. 
[70] Takahashi CD, Der-Yeghiaian L, Motiwala RR, Cramer SC. Robot-based hand motor therapy after stroke. Brain 131:425-437, 2008.

[71] Volpe BT, Krebs HI, Hogan N, Edelstein L, Diels C, Aisen M. A novel approach to stroke rehabilitation. Robot-aided sensorimotor stimulation. Neurol 54(10):1938$1944,2000$.

[72] Lo AC, Guarino PD, Richards LG, et al. Robot-assisted therapy for long-term upperlimb impairment after stroke. N Eng J Med 362:1772-1783, 2010.

[73] Krebs HI, Ferraro M, Buerger SP, Newbery MJ, Makiyama A, Sandmann M, Lynch D, Volpe BT, Hogan N. Rehabilitation robotics: pilot trial of spatial extension for MITManus. J Neuroengineer Rehabil1:5-19, 2004.

[74] Buch E, Weber C, Cohen LG, Braun C, Dimyan MA, Ard T, Mellinger J, Caria A, Soekadar S, Fourkas A, Birbaumer N. Think to move: a neuromagnetic braincomputer interface (BCI) system for chronic stroke. Stroke 39(3):910-917, 2008.

[75] Broetz D, Braun C, Weber C, Soekadar SR, Caria A, Birbaumer N. Combination of brain-computer interface training and goal-directed physical therapy in chronic stroke: a case study. Neurorehabil Neural Repair 24(7):674-679, 2010.

[76] Bradberry TJ, Gentili RJ, Contreras-Vidal JL. Reconstructing three-dimensional hand movements from noninvasive electroencephalographic signals. J Neurosci 30(9):3432-3437, 2010.

[77] Saposnik G, Levin M. Outcome Research Canada (SORCan) Working Group. Virtual reality in stroke rehabilitation: a meta-analysis and implications for clinicians. Stroke 42(5):1380-1386, 2011.

[78] Henderson AH. Virtual reality in stroke rehab: a systematic review for upper motor recovery. Top Stroke Rehabil 14(2):52-61, 2007.

[79] Jorgensen HS, Reith H, Nakayama H, Kammersgaard LP, Raaschou H, Olsen TS. What determines good recovery in patients with the most severe stroke. The Copenhagen Stroke Study. Stroke 30:2008-2012, 1999.

[80] Al-Eithan MH, Amin M, Robert AA) The effect of hemiplegia/hemiparesis, diabetes, and hyperteniosn on hospital length of stay after stroke. Neurosci 16(3):253-256, 2011.

[81] Lynch JK, Hirtz DG, DeVeber G, Nelson KB. Report of the National Institute of Neurological Disorders and Stroke workshop on perinatal and childhood stroke. Pediatr 109:116-123, 2002.

[82] deVeber G. Roach ES, Riela AR, Wiznitzer. Stroke in children: recognition, treatment, and future directions. Sem Pediatr Neurol 7(4):309-317, 2000.

[83] Giroud M, Lemesele M, Gouyon JB, Nivelon JL, Milan C, Dumas R. Cerebrovascular disease in children under 16 years of age in the city of Dijion, France: a study of incidence and clinical features from 1985 to 1993, J Clin Epidemiol 48:1343-1348, 1995.

[84] Christerson S, Stromber B. Childhood stroke in Sweden 1: incidence, symptoms, risk factors, and short-term outcome. Acta Paediatr Scand 99:1641-1649, 2010.

[85] Yock-Corrales A, Mackay MT, Mosley I, Maixner W, Baabl FE, Acute childhood arterial ischemic and hemorrhagic stroke in the emergency department. Ann Em Med 58(2):156-163, 2011.

[86] Nelson KB, Dambrosia JM, Grether JK, Phillips TM. Neonatal cytokines and coagulation factors in children with cerebral palsy. Ann Neurol 44:665-675, 1998. 
[87] Dizon-Townson D, Miller C, Sibai B, Spong CY, Thom E, Wendel G Jr, Wensgtrom K, Samuels P, Cotroneo MA, Moawad A, Sorokin Y, Meis P, Miodovnik M, O'Sullivan MJ, Conway D, Wapner RJ, Gabbe SG. The relationship of the factor V Leiden mutation and pregnancy outcome s for mother and fetus. Obste Gynecol 106(3):517$524,2005$.

[88] Gadian DG, Issacs EB, Cross JH, Connelly A, Jackson GD, King MD, Neville BG, Vargha-Khadem F. Lateralization of brain function in childhood revealed by magnetic resonance spectroscopy. Neurol 46(4):974-977, 1996.

[89] Vicari S, Stiles J, Stern C, Resca A. Spatial grouping activity in children with early cortical and subcortical lesion. Dev Med Child Neurol 40(2):90-94, 1998.

[90] Ganesan V, Hogan A, Shack N, Gordon A, Issacs E, Kirkham FJ. Outcome after ischemic stroke in childhood. Develop Med Child Neurol 42(7):455-461, 2000.

[91] Blom I, De Schryver EL, Kappelle LJ, Rinkel GJ, Jennekens-Schinkel A, Peters AC. Prognosis of haemorrhagic stroke in childhood: a long-term follow-up study. Dev Med Child Neurol 45:233-239, 2003.

[92] Steinlin M, Roellin K, Schroth G. long-term follow-up after stroke in childhood. Eur J Pediatr 163:245-250, 2004.

[93] Kolk A, Talvik T. Cognitive outcome of children with early-onset hemiparesis. J Child Neurol 15(9):581-587, 2000.

[94] De Schryver EL, Kappelle LJ, Jennekens-Schinkel A, Boudewyn Peters AC. Prognosis of ischemic stroke in childhood: a long-term follow-up study. Dev Med Child Neurol 42(5):313-318, 2000.

[95] Giroud M, Lemesele M, Madinier G, Manceau E, Osseby GV, Dumas R. Stroke in children under 16 years of age. Clinical and etiological difference with adults. Acta Neurol Scand 96(6):401-406, 1997.

[96] Kleinman JT, gailloud P, Jordan LC. Recovery from spatial neglect and hemiplegia in a child despite a large anterior circulation stroke and Wallerian degeneration. J Child Neurol 25(4):500-503, 2010.

[97] Schoenberg BS, Mellinger JF, Schoenberg DG. Cerebrovascular disease in infants and children: a study of incidence, clinical features, and survival. Neurol 28(8):763-768, 1978.

[98] Dusser A, Goutieres F, Aicardi J. Ischemic strokes in children. J Child Neurol 1(2):131136, 1986.

[99] Delsing BJ, Catsman-Berrevoets CE, Appel IM. Early prognostic indicators of outcome in ischemic childhood stroke. Pediatr Neurol 24(4):283-289, 2001.

[100] Abram HS, Knepper LE, Warty VS, Painter MJ. Natural history, prognosis, and lipid abnormalities of idiopathic ischemic childhood stroke. J Child Neurol 11(4):276-282, 1996. 
(C) 2012 The Author(s). Licensee IntechOpen. This is an open access article distributed under the terms of the Creative Commons Attribution 3.0 License, which permits unrestricted use, distribution, and reproduction in any medium, provided the original work is properly cited. 